\title{
Original
}

Journal of Hard Tissue Biology 23[3] (2014) 295-302

\section{Urinary Nickel Ion Evaluation of Adolescents during the Initial Period of Orthodontic Fixed Treatment}

\author{
Yongjuan Guo, Yi Liu, Ying Zheng, Na An and Lu Bai
}

\author{
Fengtian Dental Clinic, School of Stomatology, China Medical University, Shenyang, China \\ (Accepted for publication, April 16, 2014)
}

\begin{abstract}
Biocompatibility and resistance to biodeterioration of materials has been studied using various approaches, including the analysis of various markers of exposure, both in vitro and in vivo. The possible release of trace elements during orthodontic treatment and their potential toxicity to patients have been an increasing concern. The wide range of appliances routinely used during orthodontic treatment is typically made of alloys which may contain cobalt, chromium, iron, nickel, and titanium, of which the major concern is nickel. Nickel concentrations in humans undergoing orthodontic treatment have been assessed in many investigations, although few have specifically examined urine specimens. Urinary nickel concentrations can reflect systemic levels in whole organisms, and as a non-invasive means of study, urine analysis can easily achieve the compliance of participants and guardians. In addition, the predominant metabolic route of nickel is through the kidneys. Therefore, urinary samples are seen as a good indicator for monitoring trace metals released from orthodontic appliances. According to the literature, metal ions are released only in the initial stage of the treatment. Thus, the duration of our study was limited to the first 6 months of treatment. Since urinary nickel levels of adolescents in the initial period of fixed orthodontic treatment are being investigated and reported for the first time in this paper, the aim of our study is to quantitatively evaluate urinary nickel levels and further to summarize the dynamic metabolic regularity of systemic nickel for adolescents in the initial period of fixed orthodontic treatment.
\end{abstract}

Key words: Fixed orthodontic treatment, Initial treatment period, Urinary nickel release, Adolescence

\section{Introduction}

With the development and improvement of orthodontic fixed appliances, different types of malocclusions could be corrected with accurate and precise teeth positioning. However, the orthodontic devices would permanently interact with the chemical and physical stimulations of oral physiological environment, such as variable $\mathrm{pH}$ values, dietary intake, temperature, dental plaque, mechanical fatigue and so on ${ }^{1-10)}$, thus a question arises about potential biosafety considerations for such a therapy.

Fixed appliances routinely applied contain a wide range of metal elements, among which the major concern is nickel. The scientists suspect that the accumulation of nickel ions released from orthodontic fixed appliances may occur at different levels in different tissues ${ }^{2,8,11-13)}$, which might a chronic risk factor to physical health and could affect biological functions of the whole organism. Therefore, many studies concerned with the degradation of fixed orthodontic appliances had been investigated.

The elements of fixed appliances are manufactured mainly from two types of alloys: stainless steel (SS) and nickel-titanium

Correspondence to: Yi Liu, MD, PhD, Fengtian Dental Clinic, School of Stomatology, China Medical University, Fengtian street 359\#, Shen He District Shenyang 110013, China;Tel:+86 24 31973999; Fax: +86 24 31973999; E-mail: liuyi256@126.com
(Ni-Ti) alloys, which respectively contain approximately $8 \%$ and $47-50 \%$ nickel elements ${ }^{10,15}$. Fixed appliances might be the major source of exposure to nickel in the orthodontic patients. While nickel is not only an essential, but also a allergenic, mutagenic, carcinogenic and cytotoxic trace element, which could cause contact dermatitis, immunodeficiency, cancer, and even birth defects ${ }^{1,8-11,15-17)}$.

Due to the concern about the possible releasing of nickel and potential adverse effects on patients with fixed devices, many investigations under in vitro and in vivo conditions are widely carried on to assess exposure to nickel from orthodontic appliances in order to detect their biodeterioration and biocompatibility.

Most of in vitro experiments confirmed that the nickel ions were released in measurable amount from Ni-containing alloys immersed the solution of artificial saliva ${ }^{10,18-20}$. Cytotoxicity assays in vitro media further revealed that the nickel ions released had potential cytotoxic and genotoxic effects on cells, which may induce the DNA damage and reduce the cellular viability ${ }^{16,21)}$. Besides, various biomarkers of exposure are also widely used in the in vivo tests (e.g., saliva, serum, dental plaque, mucosa cells or urine), the general conclusion of which is that metal nickel ions were released from the initial stage of the treatment, and may have an influence on the systemic alterations of nickel 
J.Hard Tissue Biology Vol. 23(3):295-302, 2014

Table 1. Baseline Parameters of Adolescents between the Sexes.

\begin{tabular}{llllllll}
\hline \multirow{2}{*}{ Parameters } & \multicolumn{2}{c}{ Boy $(\mathrm{n}=15)$} & & \multicolumn{2}{c}{$\operatorname{Girl}(\mathrm{n}=16)$} & Student & \multirow{2}{*}{ P-value } \\
\cline { 2 - 3 } \cline { 5 - 6 } & Mean & SD & & Mean & SD & t-test & \\
\hline Age (year) & 12.08 & 0.83 & & 12.85 & 0.91 & -1.53 & 0.96 \\
Height $(\mathrm{m})$ & 1.6 & 0.08 & & 1.55 & 0.86 & 1.92 & 0.17 \\
Weight $(\mathrm{kg})$ & 49.23 & 6.06 & & 43.03 & 6.04 & 3.68 & 0.6 \\
BMI $\left(\mathrm{kg} / \mathrm{m}^{2}\right)$ & 19.13 & 1.08 & & 17.93 & 1.55 & 3.33 & 0.43 \\
\hline
\end{tabular}

Table 2. Descriptive Statistics of the Urinary Nickel Levels at Each Time Interval $(\mu \mathrm{g} / \mathrm{l})$

\begin{tabular}{llllllll}
\hline Period & N & Mean & SD & \multicolumn{2}{c}{$95 \%$ CI } & \multirow{2}{*}{ Minimum } & Maximum \\
\cline { 5 - 6 } & & & & Lower & Upper & & \\
\hline T0 & 31 & 2.01 & 0.93 & 1.67 & 2.35 & 0.213 .41 & \\
T1 & 31 & 7.01 & 0.81 & 6.72 & 7.31 & 5.11 & 8.33 \\
T2 & 31 & 4.85 & 0.82 & 4.55 & 5.15 & 3.41 & 6.54 \\
T3 & 31 & 4.54 & 0.9 & 4.21 & 4.88 & 3.03 & 6.25 \\
\hline
\end{tabular}

concentrations ${ }^{3,6,7,11,22-26)}$.

Nickel changes of humans with orthodontic treatment had been assessed in many investigations, but few of which chose urine as the determined biomarker. The investigation by Menezes et al. ${ }^{25)}$ assessed urinary samples from 21 orthodontic patients, and concluded that urinary nickel levels increased obviously 2 months after treatment (pre-treatment: $17.67 \pm 5.47 \mu \mathrm{g} / 1$, posttreatment: $19.89 \pm 3.43 \mu \mathrm{g} / \mathrm{l} ; \mathrm{p}=0.027)$. Therefore, the purpose of this study was to quantitatively evaluate urinary nickel levels and to summarize the metabolic regularity for adolescents in the initial period of orthodontic fixed treatment.

\section{Materials and Methods}

\section{Subject recruitment}

The study was performed on a sample of 31 subjects ( 15 boys and 16 girls) with a mean age of $12.47 \pm 0.94$ years and an average body mass index (BMI) of $18.51 \pm 0.26 \mathrm{~kg} / \mathrm{m}^{2}$, who were screened and recruited consecutively among malocclusion patients seeking orthodontic treatment at the department of orthodontics from October 2012 to April 2013.The patients had to meet predefined inclusion criteria: (1) no systemic diseases or medical history of metal allergy; (2) no exposures to severe nickel pollution of the environment; (3) no any welding or extraoral orthodontic device; (4) no any metal restorations or fillings; (5) no drug addiction, alcohol or acidic carbonated beverages consumption, or smoking; (6)age within the range of 10-14 years; (7)BMI within the normal range on the basis of the age-dependent scales ${ }^{27}$; (8) no impacted teeth or congenitally missing teeth excluding the third molars; (9)no need of teeth extractions in the orthodontic plan; (10) no any additional appliances in the mouth such as hyrax, TPA.

Informed consent from the parents and the ethical approval from the China Medical University Ethics Committee were obtained.

\section{Clinical examinations}

Conventional orthodontic examinations were performed on each subject. It would be advantageous that baseline data were recorded at first visit, such as name, gender, birth date, height and weight (used to calculate the value of BMI), health conditions and so on.

\section{Collection and determination of urinary samples}

The patients and their guardians as told visited the office in the morning without breakfasts at each time intervals $(\mathrm{T} 0=$ pretreatment, $\mathrm{T} 1=1$ month of post-treatment, $\mathrm{T} 2=3$ months of posttreatment, $\mathrm{T} 3=6$ months of post-treatment). Samples were taken in a clean room assigned specifically. Each patient was instructed to collect intermedial flush by supplied with a pair of sterile gloves and a disposable plastic cup. Then the specimens were transported to sterile $1.5-\mathrm{ml}$ containers and stored at $" 4{ }^{\circ} \mathrm{C}$ until the nickel evaluation was carried on. Written and oral instructions with emphasis on possible contamination or dilution were given before sample collection. Therefore, contamination could be considered to be negligible.

The patients were placed with fixed orthodontic appliances (20 orthodontic self-ligating brackets and 0.014-inch Ni-Ti wires, the same manufacture) after the samples of $\mathrm{T} 0$ were collected. Then samples were achieved at the intervals of T1, T2 and T3 respectively in the same manner.

Urinary nickel levels were determined by an in vivo methodatomic absorption spectrophotometry (AAS), which referred to the standard WS/T 44 for urinary nickel determination and permitted the metal analysis of samples without any separation of metal ions from the biomarkers ${ }^{15,28}$. And the wavelength of nickel for analysis was $232.0 \mathrm{~nm}^{28}$. Each sample was measured three times, the mean of which was regarded as the final value. 
Yongjuan Guo et al.: Urinary Nickel Ion Evaluation

Table 3. Urinary Nickel Evaluation by ANOVA for Repeated Measurements

\begin{tabular}{lllccc}
\hline Factor & $\begin{array}{l}\text { Type III } \\
\text { Sum of } \\
\text { Squaresdf }\end{array}$ & df & $\begin{array}{l}\text { Mean } \\
\text { Square }\end{array}$ & F & Sig. \\
\hline Period $(\mathrm{T} 0 \times \mathrm{T} 1 \times \mathrm{T} 2 \times \mathrm{T} 3)$ & 219.16 & 1 & 219.16 & $948.59 * *$ & 0.000 \\
Sex $($ Boy $\times$ Girl $)$ & 10.81 & 1 & 10.81 & $5.40 *$ & 0.027 \\
Period $\times$ Sex & 0.83 & 1 & 0.83 & 3.58 & 0.069 \\
\hline
\end{tabular}

$* \mathrm{P}=.05 ; * * \mathrm{P}=.001$

( $\mathrm{T} 0=$ pre-treatment, $\mathrm{T} 1=1$ month of post-treatment, $\mathrm{T} 2=3$ months of post-treatment, $\mathrm{T} 3=6$ months of post-treatment)

Table 4. Multiple Comparisons among Four Time Intervals

\begin{tabular}{|c|c|c|c|c|c|}
\hline \multirow[t]{2}{*}{ (I) group } & \multirow[t]{2}{*}{ (J) group } & \multirow[t]{2}{*}{ Mean Difference (I-J) } & \multirow[t]{2}{*}{ Sig. } & \multicolumn{2}{|c|}{$95 \% \mathrm{CI}$} \\
\hline & & & & Lower & Upper \\
\hline \multirow[t]{3}{*}{ T0 } & $\mathrm{T} 1$ & $-5.00 * * *$ & 0.000 & -5.44 & -4.57 \\
\hline & $\mathrm{T} 2$ & $-2.84 * * *$ & 0.000 & -3.28 & -2.41 \\
\hline & $\mathrm{T} 3$ & $-2.53 * * *$ & 0.000 & -2.97 & -2.1 \\
\hline \multirow[t]{3}{*}{$\mathrm{T} 1$} & T0 & $5.00 * * *$ & 0.000 & 4.57 & 5.44 \\
\hline & $\mathrm{T} 2$ & $2.16^{* * *}$ & 0.000 & 1.73 & 2.6 \\
\hline & $\mathrm{T} 3$ & $2.47 * * *$ & 0.000 & 2.03 & 2.9 \\
\hline \multirow[t]{3}{*}{$\mathrm{T} 2$} & T0 & $2.84 * * *$ & 0.000 & 2.41 & 3.28 \\
\hline & $\mathrm{T} 1$ & $-2.16 * * *$ & 0.000 & -2.6 & -1.73 \\
\hline & $\mathrm{T} 3$ & 0.31 & 0.165 & -0.13 & 0.74 \\
\hline \multirow[t]{3}{*}{$\mathrm{T} 3$} & T0 & $2.53 * * *$ & 0.000 & 2.1 & 2.97 \\
\hline & $\mathrm{T} 1$ & $-2.47 * * *$ & 0.000 & -2.9 & -2.03 \\
\hline & $\mathrm{T} 2$ & -0.31 & 0.165 & -0.74 & 0.13 \\
\hline
\end{tabular}

( $\mathrm{T} 0=$ pre-treatment, $\mathrm{T} 1=1$ month of post-treatment, $\mathrm{T} 2=3$ months of post-treatment, $\mathrm{T} 3=6$ months of post-treatment)

\section{Statistical Analysis}

All statistical analyses were performed by the Statistical Package for Social Science computer software (SPSS for Windows, Version 16.0, Chicago, IL, USA). The distributions of the measurements were investigated with the normality test, and then parametric tests were carried on. Independent Student t-test was conducted to assess differences of baseline parameters between the sexes. The descriptive analysis was used to compute the mean and standard deviations, $95 \%$ confidence intervals (CI), and the maximum and minimums for urinary levels of each interval. Values among time intervals and between genders were assessed by repeated measurements analysis of variance (ANOVA) and the Fisher's test of least significant difference (LSD-t) was performed for multiple comparisons of each interval. Statistical significance was defined as $\mathrm{P}<0.05$.

\section{Results}

The mean and standard deviation of baseline parameters between sexes at the first encounter were analyzed using independent Student t-test, and the results were presented in Table 1 without significant differences.

The mean, standard deviation, $95 \% \mathrm{CI}$, minimum and maximum for urinary nickel levels at different intervals were given in Table 2. Assumption of Sphericity was obtained by Mauchly's Test $(\mathrm{p}=0.52)$. Statistically significant differences $(\mathrm{P}<0.05)$ in the amount of nickel discharged were observed among time periods and between sexes by ANOVA (Table 3), but there was no significant difference found by the interaction combined with time periods and genders $(\mathrm{P}=0.069)$.

The multiple comparisons of the urinary nickel concentrations among four time intervals (Table 4) demonstrated that there were significantly statistical differences $(\mathrm{P}<0.01)$ between $\mathrm{T} 0$ and $\mathrm{T} 1$, $\mathrm{T} 0$ and $\mathrm{T} 2, \mathrm{~T} 0$ and $\mathrm{T} 3, \mathrm{~T} 1$ and $\mathrm{T} 2$, and $\mathrm{T} 1$ and $\mathrm{T} 3$, while there seemed to be insignificant differences between T2 and T3 $(\mathrm{P}=0.165)$.

Fig. 1a showed the mean curves for urinary nickel changes of each individual at each time period respectively, which also reflected the biological variability among individuals. Though the 

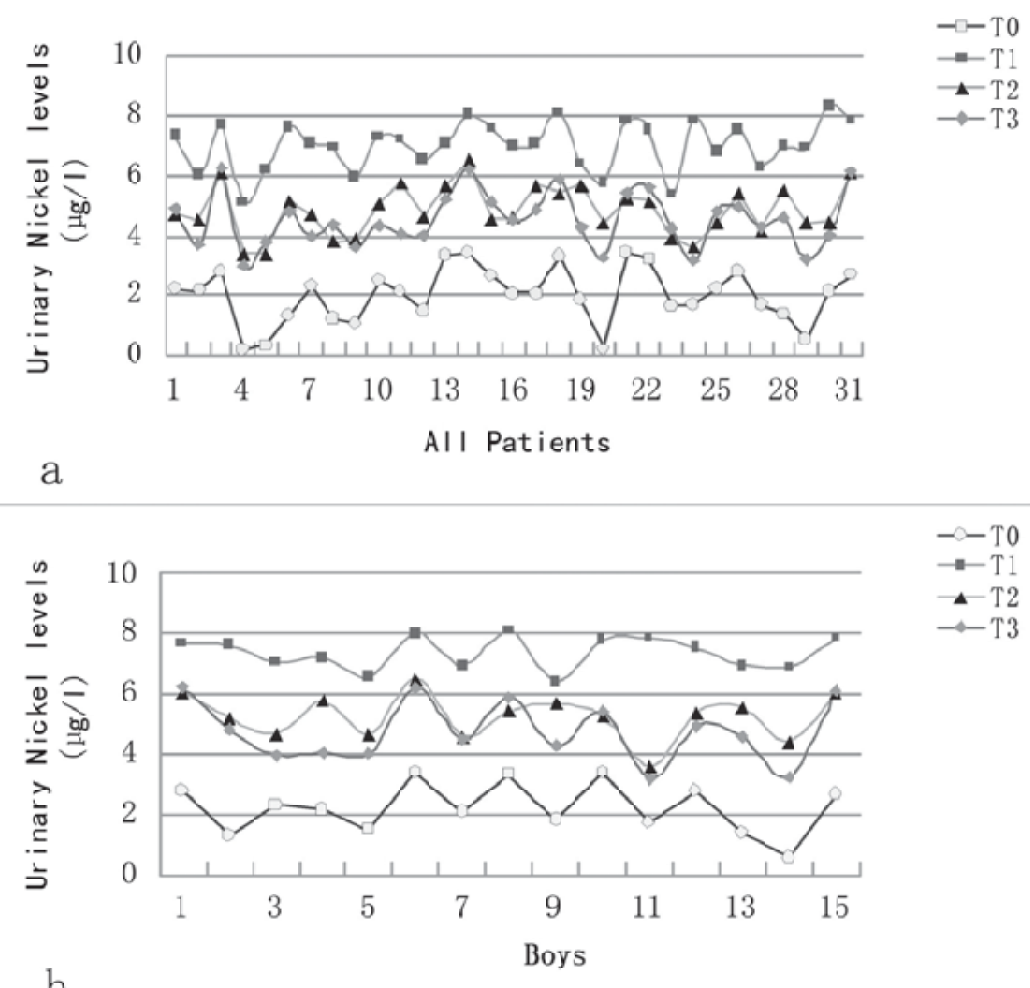

b

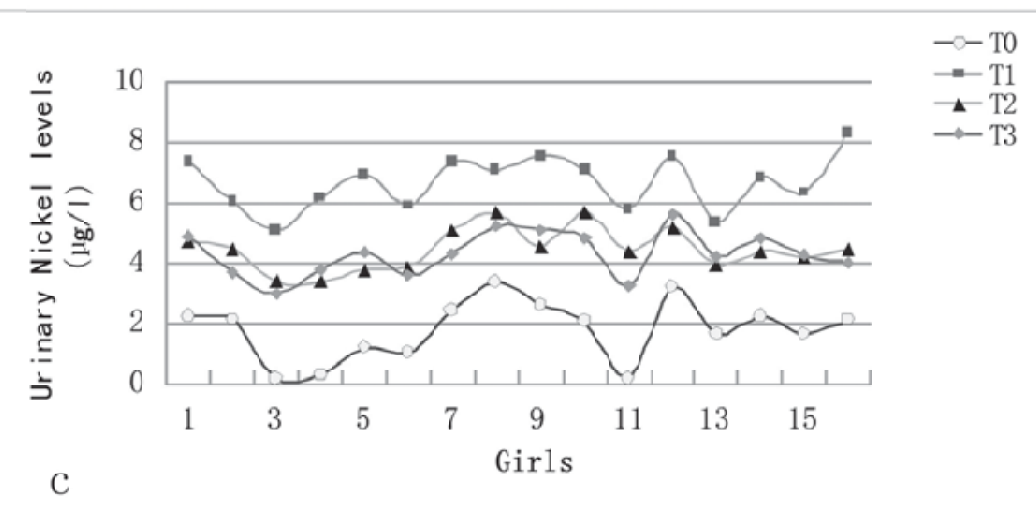

Figure 1. The mean curves for urinary nickel levels: ( a) all patients; (b) boys; (c) girls.

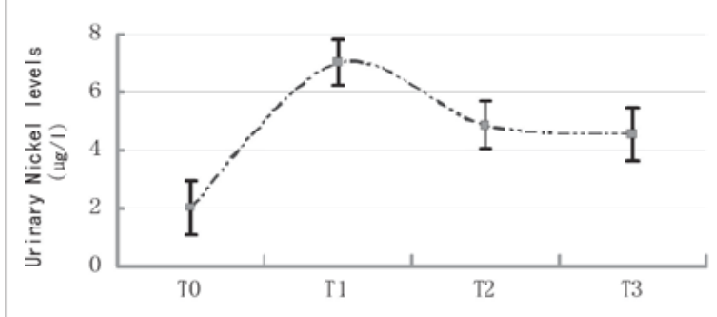

Figure 2. The curve for means and $95 \%$ CIs of each time interval.

mean levels of boys were higher than those of girls, the mean curve of boys and girls showed a similar dynamic changing trend (Fig. 1b,c).

Briefly, the amount of nickel excreted seemed to reach its highest peak at $\mathrm{T} 1$, and then it decreased obviously and finally fluctuated within a range of relatively higher levels among adolescents (Fig. 2 and Table 4). Because of no exposure to nickel, urinary levels of youngsters began to increase obviously after the appliance placement. When the dynamic metabolic balance between absorption and elimination of nickel was achieved, the urinary concentrations seem to become relatively stable.

\section{Discussion}

The predominant metabolic route of nickel was through the kidneys ${ }^{29}$. Nickel was an essential trace element of people with a range of 1.9 and $9.6 \mu \mathrm{g} / 1$ in the urine of healthy subjects ${ }^{23,25)}$, which were in harmony with our results of T0.

The patients had to meet predefined inclusion criteria, thus the major nickel source of subjects without occupational exposure was suspected to be the oral appliances. The orthodontic fixed 
Yongjuan Guo et al.: Urinary Nickel Ion Evaluation

appliances had been suffering corrosions from variable conditions of oral environment during the overall treatment. Thus it was unavoidable that the materials presented with the graded degradation. Fors et al. ${ }^{7)}$ reported that there were high levels of metals bioaccumulated in the dental plaques. The bacterial biological biofilm could induce a vasodilatation of the gingival vasculature and accelerate the gingival blood flow, which thus may facilitate the absorption of metals into the bloodstream ${ }^{3,26)}$.

Studies under in vitro conditions were quick and simple, while it was difficult to exactly reflect multivariate phenomena occurring in vivo. Salivary samples were regarded as one of the most accessible and noninvasive makers, but they may be predisposed to dilution of drinking water so that the results obtained were not reliable. Serum nickel assessment might shed light on the nickel elimination and remaining, while it was more suited for acute, rather than chronic monitoring of exposure, and achieved by an invasive means ${ }^{30}$. In addition, urinary nickel concentrations could reflect systemic levels of the whole organisms, and the noninvasive mean was beneficial to obtain satisfactory compliances of the participants and guardians. Therefore, in order to detect the systemic levels, urinary samples were developed as a good indicator to monitor chronic exposure to trace metals released from orthodontic appliances, which could provide evidence of accumulation for the whole organisms ${ }^{30}$.

Since great attention were paid to minimize possible contamination of the specimens by supplying disposable and uncontaminated containers and gloves to each patient and by informing them the possible sources of contamination, the contamination during collection and analysis seemed to be a minor problem. What was more, in order to reduce the impacts of the biological differences between individuals as well as dietary and oral hygiene habits, the nickel levels of pretreatment were chosen as baseline values for each patient. Besides, the BMI was taken into consideration for that overweigh and obesity were related with many metabolic problems ${ }^{32,33)}$. In addition, ascribed to the properties of shape memory and superelasticity, Ni-Ti wires are widely applied for initial alignment. Therefore, Ni-Ti wires and 20 brackets from the same manufacturer and same lot number were chosen as the regular fixed devices.

So far various advanced analytic techniques were widely performed to assess metal ions in order to detect their biodeterioration and biosafety. The reliable experimental results were based on the strict quality assurance during analytic procedure and adequate analytic validation. The $\mathrm{AAS}^{30,34)}$ permitted the analysis of metals in specimens without any separation of ions from the biological matrix, thus there was no need for extraction procedures to analyze the metal elements. In addition, AAS was well known to be a very sensitive analytic technique in trace metal analyses, the lower detection limit of which could be up to 0.01 $\mu \mathrm{g} / 1$.
According to literatures ${ }^{22-26)}$, metal ions were released only in the initial stage of the treatment, thus the time duration of our study was defined as first 6 months of the initial treatment. Compared with levels of pre-treatment, the amount of nickel excreted after treatment increased significantly. In this study, the mean nickel levels of T1, T2 and T3 were 3.48-fold, 2.26-fold and 2.41-fold higher than that of T0, respectively. The study concluded that nickel ions released from orthodontic devices could affect the systemic urinary changes of nickel, which was consistent with the results of other investigations ${ }^{25)}$.

According to our results, urinary concentrations were suspected to reach its peak at $\mathrm{T} 1$, then decreased gradually and finally fluctuated within a certain range. Because of no exposure to nickel, urinary levels of youngsters began to increase obviously after the appliance placement. When the dynamic metabolic balance between absorption and elimination of nickel was achieved, the urinary concentrations seem to become relatively stable.

The majority of patients in need of orthodontic treatment were adolescents at the pubertal growth (10-14 years of age). Owing to potential metabolic and biological differences, significant changes were found between the sexes, even though baseline characteristics of the genders were taken into consideration for possible confounders. However, there was no significant difference found by the interaction combined with time periods and sexes.

The mean urinary nickel levels were $4.5 \mu \mathrm{g} / \mathrm{L}$ for people without nickel expose $\mathrm{e}^{23,25}$, which were supported by the findings of this report. Our study showed that urinary levels of patients with fixed appliances (T0, T1 and T2) were obviously higher than those without wearing (T0). So fixed appliances were suspected to be the major source of exposure to nickel in the orthodontic patients. Therefore, the toxic effects of may be more detectable for the younger children with orthodontic treatment.

In conclusion, the urinary nickel levels of adolescents could be affected significantly by orthodontic fixed appliances, which may be associated with sampling time periods and genders. And then, there seemed to be a metabolic regularity for adolescents in the initial period of orthodontic fixed treatment. At last, our findings showed that determination of metals irons in urine was a useful biomarker of exposure to metals of orthodontic patients.

\section{Acknowledgements}

This research was supported in part by Liaoning Province Science and Technology Project (2013225090) from China.

\section{References}

1. Amini F, Rakhshan V and Mesgarzadeh N. Effects of longterm fixed orthodontic treatment on salivary nickel and chromium levels: A 1-year prospective cohort study. Biol Trace Elem Res 150: 15-20, 2012

2. Amini F, Jafari A, Amini P and Sepasi S. Metal ion release 
from fixed orthodontic appliances - an in vivo study. Eur J Orthod 34: 126-130, 2012

3. Mikulewicz M and Chojnacka K. Cytocompatibility of medical biomaterials containing nickel by osteoblasts: A systematic literature review. Biol Trace Elem Res 142: 865889, 2001

4. Kuhta M, Pavlin D, Slaj M, Varga S, Lapter-Varga M and Slaj M. Type of arch wire and level of acidity: Effects on the release of metal ions from orthodontic appliances. Angle Orthod 79: 102-110, 2009

5. Freitas MP, Oshima HM and Menezes LM. Release of toxic ions from silver solder used in orthodontics: An in-situ evaluation. Am J Orthod Dentofac Orthop 140: 177-181, 2011

6. Aðaoðlu G, Arun T, Izgi B and Yarat A. Nickel and chromium levels in the saliva and serum of patients with fixed orthodontic appliances. Angle Orthod 71: 375-379, 2001

7. Fors R and Persson M. Nickel in dental plaque and saliva in patients with and without orthodontic appliances. Eur J Orthod 28: 292-297, 2006

8. Re: de Souza RM and de Menezes LM. Nickel, chromium and iron levels in the saliva of patients with simulated fixed orthodontic appliances. Angle Orthod 78: 345-350, 2008

9. House K, Sernetz F, Dymock D, Sandy JR, Ireland AJ.Corrosion of orthodontic appliances-should we care?.Am J Orthod Dentofac Orthop 133:584-592,2008

10. Eliades $\mathrm{T}$, Athanasiou $\mathrm{AE}$ In vivo aging of orthodontic alloys: implications for corrosion potential, nickel release, and biocompatibility. Angle Orthod 72:222-237,2002.

11. Amini F, Borzabadi Farahani A, Jafari A and Rabbani M. In vivo study of metal content of oral mucosa cells in patients with and without fixed orthodontic appliances. Orthod Craniofac Res 11: 51-56, 2008

12. Singh DP, Sehgal V, Pradhan KL, Chandna A and Gupta R. Estimation of nickel and chromium in saliva of patients with fixed orthodontic appliances. World J Orthod 9: 196-202, 2008

13. Afridi HI, Kazi TG, Kazi NG, Jamali MK, Arain MB, Sirajuddin, Baig JA, Kandhro GA, Wadhwa SK and Shah AQ. Evaluation of cadmium, lead, nickel and zinc status in biological samples of smokers and nonsmokers hypertensive patients. J Hum Hypertens 24: 34-43, 2010

14. Petoumeno E, Kislyuk M, Hoederath H, Keilig L, Bourauel $\mathrm{C}$ and Jager A. Corrosion susceptibility and nickel release of nickel titanium wires during clinical application. J Orofac Orthop 69: 411-423, 2008

15. Kerosuo H, Moe $\mathrm{G}$ and Kleven E. In vitro release of nickel and chromium from different types of simulated orthodontic appliances. Angle Orthod 65: 111-116, 1995

16. Fernández-Miñano E, Ortiz C, Vicente A, Calvo JL and
Ortiz AJ. Metallic ion content and damage to the DNA in oral mucosa cells of children with fixed orthodontic appliances. Biometals 24: 935-941, 2011

17. Jergovic M, Miskulin M, Puntaric D, Gmajnic R, Milas J and Sipos L. Cross-sectional biomonitoring of metals in adult populations in post-war eastern Croatia: Differences between areas of moderate and heavy combat. Croat Med J 51: 451460,2010

18. Elshahawy W, Watanabe I and Koike M. Elemental ion release from four different fixed prosthodontic materials. Dent Mater 25: 976-981, 2009

19. Karnam SK, Reddy AN and Manjith CM. Comparison of Metal Ion Release from different bracket archwire combinations: An in vitro study. J Contemp Dent Pract 13: 376-381, 2012

20. Gürsoy S, Acar AG and $\mathrm{Se}^{\mathrm{o} e n ~ C . ~ C o m p a r i s o n ~ o f ~ m e t a l ~ r e l e a s e ~}$ from new and recycled bracket-archwire combinations. Angle Orthod 75: 92-94, 2004

21. Messer RL and Lucas LC. Cytotoxicity of nickel-chromium alloys bulk alloys compared to multiple ion salt solutions. Dent Mater 16: 207-212, 2000

22. Eliades T, Trapalis C, Eliades G and Katsavrias E. Salivary metal levels of orthodontic patients: A novel methodological and analytical approach. Eur J Orthod 25: 103-106, 2003

23. Bishara SE, Barrett RD and Selim MI. Biodegradation of orthodontic appliances. Part II. Changes in the blood level of nickel. Am J Orthod Dentofacial Orthop 103: 115-119, 1993

24. Faccioni F, Franceschetti P, Cerpelloni M and Fracasso ME. In vivo study on metal release from fixed orthodontic appliances and DNA damage in oral mucosa cells. Am J Orthod Dentofacial Orthop 124: 687-694, 2003

25. Menezes LM, Quintao CA and Bolognese AM. Urinary excretion levels of nickel in orthodontic patients. Am J Orthod Dentofacial Orthop 131: 635-638, 2007

26. Mikulewicz M and Chojnacka $\mathrm{K}$. Trace metal release from orthodontic appliances by in vivo studies: A systematic literature review. Biol Trace Elem Res 137: 127-138, 2010

27. Cole TJ, Bellizzi MC, Flegal KM and, Dietz WH. Establishing a standard definition for child overweight and obesity worldwide: International survey. BMJ 320: 1240, 2000

28. WS/T-1996. Urine determination of nickel graphite furnace atomic absorption spectrometric method (S). Standards Press of China, Beijing, China. 1997. 1-3.

29. Leikin JB and Paloucek FP. Poisoning and toxicology handbook. 4th ed. Informa Healthcare, Chicago, USA. 2007.

30. Olmedo P, Pla A, Hernandez AF, Lopez-Guarnido O and Gil F. Validation of a method to quantify chromium, cadmium, manganese, nickel and lead in human whole blood, urine, 
Yongjuan Guo et al.: Urinary Nickel Ion Evaluation

saliva and hair samples by electrothermal atomic absorption spectrometry. Anal Chim Acta 659: 60-67, 2010

31. Rodrigues JL, Batista BL, Nunes JA, Passos Carlos JS and Barbosa F. Evaluation of the use of human hair for biomonitoring the deficiency of essential and exposure to toxic elements. Sci Total Environ 405: 370-376, 2008

32. Lee HA and Park H. Overview of noncommunicable diseases in Korean children and adolescents: Focus on obesity and its effect on metabolic syndrome. J Prev Med Public Health
46: 173-182, 2013

33. Abrams P, Levitt and Katz LE. Metabolic effects of obesity causing disease in childhood. Curr Opin Endocrinol Diabetes Obes 18: 23-27, 2011

34. Oliveira JP, de Siqueira ME and da Silva CS. Urinary nickel as bioindicator of workers \& Ni exposure in a galvanizing plant in Brazil. Int Arch Occup Environ Health 73: 65-68, 2000 
J.Hard Tissue Biology Vol. 23(3):295-302, 2014 